\title{
A Comparison of the Protective Effects between Epigallocatechin Gallate or Epicatechin Gallate and the Mixtures of Their Components on Paraquat-Induced Oxidative Stress in Rats
}

\author{
Nozomi ANDO, ${ }^{1}$ Kiharu IGARASHI,${ }^{1 *}$ Asako TAKENAKA ${ }^{1}$ and Yukihiko HARA ${ }^{2}$ \\ 'Department of Bioresource Engineering, Faculty of Agriculture, Yamagata University, 1-23 Wakaba-machi, Turuoka-shi, Yamagata 997-8555, \\ Japan \\ ${ }^{2}$ Mitsui Norin Co., Ltd., 223-1, Miyabara, Fujieda, Shizuoka 426-0133, Japan
}

Received December 27, 1999; Accepted March 24, 2000

\begin{abstract}
The preventive effects of (-)-epigallocatechin gallate (EGCg), (-)-epigallocatechin (EGC), gallic acid (GA), and a mixture of EGC and GA, and also of (-)-epicatechin gallate (ECg), (-)-epicatechin (EC), and a mixture of EC and GA against paraquat $(\mathrm{PQ})$-induced oxidative stress were compared in rats to determine whether the preventive effects of the EGCg and ECg against oxidative stress can be obtained by a mixture of their components or not. An increase in lung weight induced by PQ feeding was relieved by supplementing EGCg or ECg to the PQ diet, and the magnitude of relief was stronger than that achived by a mixture of EGC and GA, or EC and GA. An increase in liver TBARS, and decreases in the catalase activity in liver mitochondrial fraction and in liver triacylglycerol concentration, which were all induced by PQ feeding, were also relieved or tended to be relieved more effectively by EGCg or ECg than by either of the mixtures mentioned. These results demonstrated that the preventive effects of EGCg and $\mathrm{ECg}$ in vivo cannot be obtained by ingesting the mixtures of their components.
\end{abstract}

Keywords: epigallocatechin gallate, epicatechin gallate, gallic acid, oxidative stress, paraquat, lung weight

It is well known that catechins show both in vitro (Hara, 1994) and in vivo (Igarashi et al., 1999) antioxidative activities, and also antimutagenic ( Kada et al., 1985; Yen \& Chen, 1995), antitumor (Yoshizawa et al., 1987; Susanne et al., 1996), antibacterial (Toda et al., 1991; Ikigai et al. 1993), hypocholesterolemic (Fukuyo et al., 1986) and anticomplement (Nakagami et al., 1995) activities. The physiological functions of catechins have therefore been the focal point of numerous researchers and people who drink green tea, which contains an ample amount of catechins. We previously compared the preventive effects of catechins against oxidative stress in vivo and demonstrated that such effect against paraquat-induced oxidative stress in rats was strongest in (-)-epigallocatechin gallate (EGCg), followed by (-)epicatechin gallate $(\mathrm{ECg})$ or (-)-epigallocatechin (EGC), while the activity of $(-)$-epicatechin (EC) was very weak (Igarashi et al., 1999; Igarashi et al., 1998). These results suggested that gallic acid moiety in EGCg and $\mathrm{ECg}$ molecules was very important in relieving oxidative stress in vivo. However, it has not been determined whether the preventive effects of EGCg and ECg can be obtained by ingesting the mixtures of their components, such as $\mathrm{EGC}+$ gallic acid(GA) or $\mathrm{EC}+\mathrm{GA}$.

In this experiment, the preventive effects of EGCg, EGC, GA, and $\mathrm{EGC}+\mathrm{GA}$, and of $\mathrm{ECg}, \mathrm{EC}, \mathrm{GA}$, and $\mathrm{EC}+\mathrm{GA}$ against paraquat (PQ)-induced oxidative stress were compared in rats to determine whether galloyl moiety must be present or is not needed in the state esterified with EGC or EC molecules to produce

*To whom correspondence should be addressed

E-mail: igarashi@tds1.tr.yamagata-u.ac.jp stronger preventive activity of $\mathrm{EGCg}$ and $\mathrm{ECg}$ against such stress. In addition, PQ is known as a reagent to generate active oxygen species such as superoxide anion and hydrogen peroxide through redox cycling reaction in vivo (Bismuth et al., 1990).

\section{Materials and Methods}

Catechins and paraquat $\mathrm{EGCg}, \mathrm{ECg}$, and $\mathrm{EC}$ were prepared from green tea by Mitsui Norin Co., Ltd. (Fujieda, Shizuoka). The purity level of each catechin was more than $95 \%$ when analyzed by HPLC using ODS column and a mixture of acetonitrile-ethyl acetate- $0.5 \%$ phosphoric acid $(12: 2: 86, \mathrm{v} / \mathrm{v})$ as a developing solvent. Paraquat (methyl viologen) was purchased from Sigma Co., Ltd. (St. Louis. Mo).

Animals and diets Four-week-old male Wistar strain rats (Japan SLC, Hamamatsu), each weighing about $50 \mathrm{~g}$, were fed a commercial diet for 3 days before use and were then divided into 6 groups of 5-6 rats for each experiment, 1 and 2. Each rat was housed in a stainless steel cage with a 12-h light and 12-h dark cycle (06:00-18:00), at a temperature range of $22-24^{\circ} \mathrm{C}$ and a relative humidity of about $55 \%$.

The composition of the experimental diet is given in Table 1. There were six diets for each experiment. For experiment 1: there was a basal diet without $\mathrm{PQ}$, and five $\mathrm{PQ}$ diets with or without catechins or GA : PQ, PQ+EGCg, PQ+EGC, PQ+GA and $\mathrm{PQ}+\mathrm{EGC}+\mathrm{GA}$ diets. For experiment 2: there was a basal diet without $P Q$, and five PQ diets with or without catechins or GA : $\mathrm{PQ}, \mathrm{PQ}+\mathrm{ECg}, \mathrm{PQ}+\mathrm{EC}, \mathrm{PQ}+\mathrm{GA}$ and $\mathrm{PQ}+\mathrm{EC}+\mathrm{GA}$ diets. The levels of $0.063 \%$ EGC, $0.037 \%$ GA, $0.097 \%$ ECg and $0.060 \%$ $\mathrm{EC}$ added to the basal diet were equal to the level of $0.1 \% \mathrm{EGCg}$ 
Table 1. Compositions of the diets.

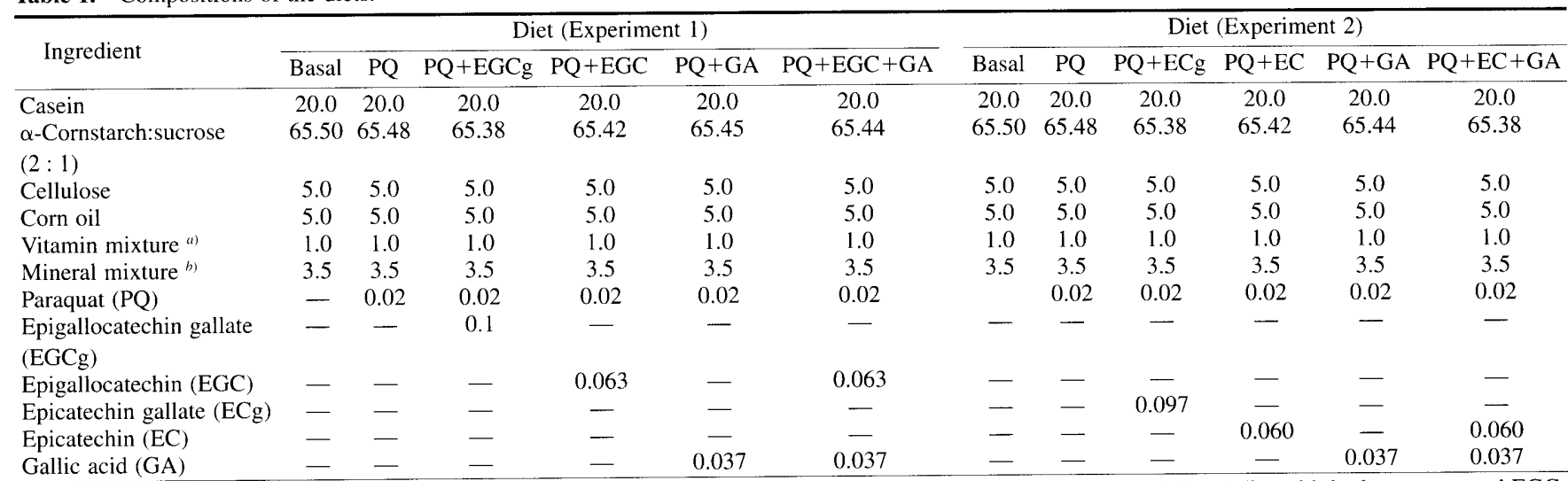

Diet: Basal, basal diet; PQ, basal diet with paraquat; PQ+EGCG, basal diet with both paraquat and EGCg; PQ+EGC, basal diet with both paraquat and EGC; $\mathrm{PQ}+\mathrm{GA}$, basal diet with paraquat and gallic acid; $\mathrm{PQ}+\mathrm{EGC}+\mathrm{GA}$, basal diet with paraquat, $\mathrm{EGC}$, and $\mathrm{GA} ; \mathrm{PQ}+\mathrm{ECg}$, basal diet with both paraquat and $\mathrm{ECg}$; $\mathrm{PQ}+\mathrm{EC}$, basal diet with both paraquat and $\mathrm{EC} ; \mathrm{PQ}+\mathrm{EC}+\mathrm{GA}$, basal diet with paraquat, $\mathrm{EC}$ and $\mathrm{GA}$.

a) AIN-93-VX and ${ }^{b}$ AIN-93G-MX (Reeves et al., 1993) were obtained from Oriental Co., Tokyo, Japan.

on a molar basis. Each catechin was added to the PQ diet in place of a mixture of $\alpha$-cornstarch and sucrose $(2: 1)$. Food and water were provided ad libitum for 11 days in experiment 1 and for 12 days in experiment 2 .

Blood and liver Blood was collected by cardiac puncture from rats that had been anesthetized with Nembutal (Dainippon Pharmaceutical Co., Osaka) after $10 \mathrm{~h}$ of starvation at the end of the feeding period. Lungs and liver were detached after blood collection and the organs were weighed. A $0.1 \mathrm{ml}$ aliquot of blood was added to $1.9 \mathrm{ml}$ of physiological saline with gentle shaking, and the mixture was then centrifuged at $1000 \times g$ for 10 min to obtain the serum for measuring the concentration of serum TBARS (thiobarbituric acid reactive substances). A section of the right lobe of the liver was used to measure catalase activity and TBARS concentration. The serum used to measure the lipid was prepared by centrifuging the blood at $1000 \times g$ for $15 \mathrm{~min}$.

Preparation of mitochondrial fraction Subcellular fractionation was carried out according to the method of Del Boccio et al. (1990). Five-tenth of a gram of the right lobe was homogenized in $2.5 \mathrm{ml}$ of ice-cold $0.1 \mathrm{M}$ phosphate buffer ( $\mathrm{pH} 7.4$ ) containing $1 \mathrm{mM}$ EDTA in a homogenizer with a Teflon pestle, and the homogenate was then mixed with 2 volumes of $2.3 \% \mathrm{KCl}$, followed by centrifugation at $600 \times \mathrm{g}$ for $3 \mathrm{~min}$ at $4^{\circ} \mathrm{C}$ to remove fibrous materials. The supernatant obtained was further centrifuged at $1400 \times \mathrm{g}$ for $10 \mathrm{~min}$ at $4^{\circ} \mathrm{C}$ to remove cellular debris. An aliquot of the supernatant was subsequently sonicated at $30 \mathrm{~W}$ for $2 \mathrm{~min}$ at $4^{\circ} \mathrm{C}$ (4 times for $30 \mathrm{~s}$ ) in a Bransonic model 1200 sonicator (Yamato Co., Tokyo). It was then centrifuged at 10,000 $\times g$ for $30 \mathrm{~min}$ at $4^{\circ} \mathrm{C}$ to obtain the mitochondrial fraction as a precipitate, which was used to measure the catalase activity.

Measurement of enzyme activities Catalase activity was measured by the spectrophotometric method, following a decrease in absorbance at $240 \mathrm{~nm}$ at $25^{\circ} \mathrm{C}$, due to the decomposition of hydrogen peroxide (Tomita \& Sano, 1983). The definition of one unit of catalase activity is the amount of enzyme required to decompose $1 \mu \mathrm{mol}$ of $\mathrm{H}_{2} \mathrm{O}_{2}$ in $1 \mathrm{~min}$ per $\mathrm{mg}$ of protein. Protein content was measured using the method of Lowry et al. (1951).

Lipid analyses The serum triacylglycerol was measured enzymatically using a commercial kit, triglyceride E-test (Wako Pure Chemical Ind.). To measure the liver triacylglycerol content, liver lipids were extracted with a mixture of chloroform and methyl alcohol $(2: 1, \mathrm{v} / \mathrm{v})$ and purified by the method of Folch $e t$ al. (1957). The amount of triacylglycerol in the lipids, which was dissolved in isopropyl alcohol after evaporating the chloroform layer, was determined using the same kit as used for the serum.

Statistical analyses The data for each of the 6 groups were statistically analyzed by Duncan's multiple range test (Duncan, 1957) after one-way analysis of variance (ANOVA) except for the food intake which was compared using Mann-Whitney test for its nonparametric data. Significant differences in the means were inspected at $p>0.05$.

\section{Results and Discussion}

The results of experiment 1 are shown in Table 2. Food intake and body weight gain significantly decreased in the rats fed the PQ diet compared to those of the basal diet-fed rats (control rats), and the decrease was relieved by supplementing EGCg or EGC to the PQ diet. The magnitude of relief tended to be stronger in the EGCg-fed rats than in the EGC-fed rats, suggesting that galloyl moiety of EGCg plays an important role in creating a stronger preventive effect of $\mathrm{EGCg}$ as reported previously (Igarashi $e t$ al., 1998). Supplemention of GA or EGC+GA to the PQ diet was also effective in lessening the decreases in food intake and body weight gain by PQ. GA and EGC+GA showed almost the same effects as did EGCg in mitigating these decreases. However, increases in lung weight ( $\%$ of body weight), liver TBARS and atherogenic index, and decreases in catalase activity in liver mitochondrial fraction and in the liver triacylglycerol concentration, which were all induced by PQ feeding, tended to be suppressed more strongly by the supplementation of $\mathrm{EGCg}$ than $\mathrm{EGC}+\mathrm{GA}$ to the PQ diet. These results appear to indicate that EGC and GA moieties in the EGCg molecule should be present in the esterified form for demonstration of stronger preventive effects against PQ-induced oxidative stress. However, since the GA molecule itself had the effect of relieving this stress, the GA molecule may also be effective in preventing oxidative stress when GA is released from EGCg in the gastrointestinal tract and then absorbed. The effect of EGCg and ECg on lowering the rise 
Table 2. Effects of EGCg and its components on the food intake, body weight gain, organ weight, serum and liver lipid concentrations, and catalase activity in rats fed the PQ diet (Experiment 1).

\begin{tabular}{|c|c|c|c|c|c|c|}
\hline & \multicolumn{6}{|c|}{ Dietary group } \\
\hline & Basal & PQ & $\mathrm{PQ}+\mathrm{EGCg}$ & $\mathrm{PQ}+\mathrm{EGC}$ & $\mathrm{PQ}+\mathrm{GA}$ & $\mathrm{PQ}+\mathrm{EGC}+\mathrm{GA}$ \\
\hline Initial body weight $(\mathrm{g})$ & $63.9 \pm 2.2$ & $63.8 \pm 0.9$ & $63.7 \pm 1.2$ & $63.7 \pm 1.6$ & $63.1 \pm 1.0$ & $63.8 \pm 1.8$ \\
\hline Food intake (g/11 days) & $111 \pm 1^{\mathrm{a}}$ & $87.5 \pm 1.8^{\mathrm{b}}$ & $111 \pm 1^{\mathrm{a}}$ & $109 \pm 0.9^{\mathrm{a}}$ & $112 \pm 1^{\mathrm{a}}$ & $111 \pm 1^{\mathrm{a}}$ \\
\hline Liver weight $(\mathrm{g})$ & $4.2 \pm 0.1^{\mathrm{a}}$ & $3.0 \pm 0.1^{\mathrm{c}}$ & $4.2 \pm 0.1^{\mathrm{a}}$ & $3.7 \pm 0.2^{b}$ & $4.0 \pm 0.2^{\mathrm{ab}}$ & $4.0 \pm 0.1^{\mathrm{ab}}$ \\
\hline Liver weight ( $\%$ of body weight) & $4.1 \pm 0.1$ & $3.8 \pm 0.1$ & $4.2 \pm 0.1$ & $3.8 \pm 0.1$ & $4.0 \pm 0.1$ & $4.0 \pm 0.1$ \\
\hline Lung weight $(\mathrm{g})$ & $0.65 \pm 0.02^{b}$ & $0.80 \pm 0.04^{\mathrm{a}}$ & $0.69 \pm 0.02^{\mathrm{b}}$ & $0.72 \pm 0.03^{b}$ & $0.73 \pm 0.01^{\mathrm{b}}$ & $0.72 \pm 0.01^{\mathrm{b}}$ \\
\hline Lung weight ( $\%$ of body weight) & $0.63 \pm 0.02^{b}$ & $0.97 \pm 0.10^{\mathrm{a}}$ & $0.68 \pm 0.02^{\mathrm{b}}$ & $0.74 \pm 0.04^{\mathrm{ab}}$ & $0.72 \pm 0.01^{\mathrm{ab}}$ & $0.73 \pm 0.01^{\mathrm{a}}$ \\
\hline Serum TBARS $(\mathrm{nmol} / \mathrm{ml}$ of blood) & $1.14 \pm 0.12$ & $1.03 \pm 0.12$ & $0.72 \pm 0.03$ & $1.05 \pm 0.14$ & $0.86 \pm 0.07$ & $0.95 \pm 0.13$ \\
\hline Liver TBARS (nmol/mg of total lipids ) & $2.22 \pm 0.16^{\mathrm{b}}$ & $3.14 \pm 0.21^{a}$ & $2.18 \pm 0.07^{b}$ & $2.72 \pm 0.34^{\mathrm{ab}}$ & $2.60 \pm 0.14^{\mathrm{ab}}$ & $2.52 \pm 0.12^{\mathrm{b}}$ \\
\hline Atherogenic index ${ }^{2)}$ & $0.22 \pm 0.02^{\mathrm{b}}$ & $0.36 \pm 0.05^{a}$ & $0.13 \pm 0.05^{\mathrm{b}}$ & $0.16 \pm 0.03^{\mathrm{b}}$ & $0.23 \pm 0.03^{b}$ & $0.20 \pm 0.03^{\mathrm{b}}$ \\
\hline $\begin{array}{l}\text { Catalase activity in liver } \\
\text { mitochondrial fraction } \\
\text { (U/mg of protein) }\end{array}$ & $503 \pm 69^{a}$ & $105 \pm 18^{c}$ & $344 \pm 48^{b}$ & $268 \pm 47^{b}$ & $350 \pm 69^{\mathrm{b}}$ & $301 \pm 33^{\mathrm{b}}$ \\
\hline Serum triacyl glycerol $(\mathrm{mmol} / l)$ & $0.60 \pm 0.08^{\mathrm{a}}$ & $0.26 \pm 0.01^{\mathrm{cd}}$ & $0.51 \pm 0.07^{\mathrm{ab}}$ & $0.35 \pm 0.03^{c}$ & $0.49 \pm 0.07^{\mathrm{ab}}$ & $0.42 \pm 0.06^{\mathrm{abc}}$ \\
\hline Liver triacylglycerol (mmol/g of liver) & $9.65 \pm 0.57^{\mathrm{ab}}$ & $2.34 \pm 0.33^{d}$ & $11.5 \pm 0.6^{\mathrm{a}}$ & $5.72 \pm 1.11^{c}$ & $9.76 \pm 0.72^{\mathrm{ab}}$ & $7.77 \pm 0.78^{\mathrm{bc}}$ \\
\hline
\end{tabular}

Each result is expressed as the mean $\pm S E$ of 5 or 6 rats per group. Values within the same row and not sharing a common superscript letter are significantly different at $p<0.05$.

1) Total lipids were extracted with chloroform-methanol $(2: 1)$ by the method of Folch et al. (1957).

2) (Total cholesterol-HDL-cholesterol)/HDL-cholesterol.

Table 3. Effects of ECg and its components on the food intake, body weight gain, organ weight, serum and liver lipid concentrations, and catalase activity in rats fed the PQ diet (Experiment 2).

\begin{tabular}{|c|c|c|c|c|c|c|}
\hline & \multicolumn{6}{|c|}{ Dietary group } \\
\hline & Basal & PQ & $\mathrm{Q}+\mathrm{ECg}$ & $P Q+E C$ & $\mathrm{PQ}+\mathrm{GA}$ & $\mathrm{PQ}+\mathrm{EC}+\mathrm{GA}$ \\
\hline Initial body weight $(\mathrm{g})$ & $62.9 \pm 1.0$ & $62.9 \pm 0.7$ & $62.9 \pm 1.0$ & $62.9 \pm 1.1$ & $62.9 \pm 1.0$ & $62.9 \pm 1.0$ \\
\hline Food intake ( $\mathrm{g} / 12$ days) & $120 \pm 1^{\mathrm{a}}$ & $101 \pm 3^{\mathrm{d}}$ & $119 \pm 1^{\text {ab }}$ & $113 \pm 2^{a b c}$ & $114 \pm 1.7^{c}$ & $114 \pm 2^{b c}$ \\
\hline Body weight gain (g/12 days) & $41.3 \pm 1.0^{c}$ & $20.6 \pm 3.1^{\mathrm{c}}$ & $42.9 \pm 0.9^{\mathrm{a}}$ & $32.0 \pm 2.3^{\mathrm{b}}$ & $37.3 \pm 2.0^{\mathrm{ab}}$ & $34.8 \pm 2.7^{\mathrm{b}}$ \\
\hline Liver weight $(\mathrm{g})$ & $4.0 \pm 0.1^{a}$ & $3.1 \pm 0.1^{\mathrm{c}}$ & $4.1 \pm 0.1^{\mathrm{a}}$ & $3.5 \pm 0.2^{\mathrm{bc}}$ & $3.9 \pm 0.2^{\mathrm{ab}}$ & $3.6 \pm 0.3^{\mathrm{ab}}$ \\
\hline Liver weight ( $\%$ of body weight) & $3.8 \pm 0.1$ & $3.8 \pm 0.2$ & $3.9 \pm 0.1$ & $3.4 \pm 0.1$ & $3.9 \pm 0.1$ & $3.7 \pm 0.2$ \\
\hline Lung weight $(\mathrm{g})$ & $0.66 \pm 0.12^{\mathrm{d}}$ & $0.81 \pm 0.03^{\mathrm{a}}$ & $0.69 \pm 0.02^{\mathrm{cd}}$ & $0.78 \pm 0.02^{\mathrm{ab}}$ & $0.74 \pm 0.02^{\text {bc }}$ & $0.72 \pm 0.02^{\mathrm{bcd}}$ \\
\hline Lung weight ( $\%$ of body weight) & $0.63 \pm 0.01^{d}$ & $1.1 \pm 0.2^{\mathrm{a}}$ & $0.65 \pm 0.02^{d}$ & $0.81 \pm 0.02^{\mathrm{ab}}$ & $0.74 \pm 0.03^{\mathrm{bc}}$ & $0.74 \pm 0.02^{c}$ \\
\hline Serum TBARS $(\mathrm{nmol} / \mathrm{ml}$ of blood) & $2.52 \pm 0.12$ & $2.76 \pm 0.23$ & $2.50 \pm 0.19$ & $2.74 \pm 0.13$ & $2.94 \pm 0.21$ & $2.53 \pm 0.08$ \\
\hline Liver TBARS (nmol/mg of total lipids) $\left.{ }^{b}\right)$ & $3.64 \pm 0.43^{\mathrm{b}}$ & $6.65 \pm 0.83^{\mathrm{a}}$ & $5.18 \pm 0.16^{\mathrm{ab}}$ & $5.64 \pm 0.62^{\mathrm{a}}$ & $5.49 \pm 0.5 \mathrm{l}^{\mathrm{a}}$ & $5.19 \pm 0.56^{\mathrm{ab}}$ \\
\hline Atherogenic index ${ }^{2)}$ & $0.36 \pm 0.04^{b}$ & $0.48 \pm 0.11^{\mathrm{a}}$ & $0.35 \pm 0.05^{\mathrm{a}}$ & $0.34 \pm 0.04^{\mathrm{a}}$ & $0.33 \pm 0.04$ & $0.31 \pm 0.05^{a}$ \\
\hline $\begin{array}{l}\text { Catalase activity in liver } \\
\text { mitochondrial fraction (U/mg of protein) }\end{array}$ & $807 \pm 63^{a}$ & $409 \pm 22^{b}$ & $712 \pm 31^{a}$ & $471 \pm 30^{\mathrm{b}}$ & $550 \pm 56^{\mathrm{b}}$ & $477 \pm 62^{b}$ \\
\hline Serum triacylglycerol $(\mathrm{mmol} / l)$ & $0.34 \pm 0.05$ & $0.39 \pm 0.07$ & $0.44 \pm 0.05$ & $0.38 \pm 0.03$ & $0.46 \pm 0.04$ & $0.36 \pm 0.02$ \\
\hline Liver triacylglycerol ( $\mu \mathrm{mol} / \mathrm{g}$ of liver) & $36.3 \pm 1.3^{\mathrm{a}}$ & $9.83 \pm 3.70^{\mathrm{c}}$ & $27.5 \pm 1.8^{\mathrm{ab}}$ & $18.6 \pm 3.8^{\mathrm{bc}}$ & $20.5 \pm 4.1^{\mathrm{b}}$ & $27.2 \pm 4.3^{\mathrm{ab}}$ \\
\hline
\end{tabular}

Each result is expressed as the mean \pm SE of 5 or 6 rats per group. Values within the same row and not sharing a common superscript letter are significantly different at $p<0.05$.

1) Total lipids were extracted with chloroform-methanol $(2: 1)$ by the method of Folch et al. (1957).

2) (Total cholesterol-HDL-cholesterol)/ HDL-cholesterol.

in the atherogenic index in PQ-fed rats should be investigated in more detail using model animals with atherosclerosis, because some properties of lipoprotein differ between human and rat (Van'T Hooft \& Van Tol, 1985)

The reason the preventive effects of $\mathrm{EGC}+\mathrm{GA}$ were almost equal to those of GA remained unexplained, because EGC also showed significant prevention on reductions in body weight gain, catalase activity and liver triacylglycerol concentration, and increases in lung weight and atherogenic index; it is believed that the effects of EGC+GA are the sum of the respective effects of EGC and GA.

Since it was demonstrated previously that the preventive effects of ECg against PQ-induced oxidative stress were considerably stronger than those of $\mathrm{EC}$, which showed almost none (Igarashi et al., 1999), the effects of ECg, EC, GA and EC+GA against oxidative stress were also compared to learn whether the effect of $\mathrm{ECg}$ can be obtained by a mixture of EC and GA.
The preventive effects of ECg on decreases in body weight gain and catalase activity in the liver mitochondrial fraction, and on increase in lung weight, all of which were induced by PQ feeding, were significantly stronger than those of $\mathrm{EC}+\mathrm{GA}$, indicating that the effects of ECg cannot be obtained by the mixture of $\mathrm{EC}$ and GA. In contrast, the preventive effects of $\mathrm{ECg}$ on decreases in catalase activity and increases in lung weight (\%) by PQ were significantly stronger than those of GA. These results seem to further suggest that the effects of ECg are not obtained when EC was mixed with GA, and that GA in the ECg may be more effective in preventing oxidative stress when it is present in the esterified state with EC rather than in free form.

Although differences in the magnitude of interactions between PQ and EGCg, EGC, ECg, EC or GA in the gastrointestinal tract are believed to cause the differences in preventive effects among $\mathrm{EGCg}, \mathrm{EGC}$ and $\mathrm{EGC}+\mathrm{GA}$, and among ECg, EC and EC+GA, these interactions in the gastrointestinal tract may be negligibly 
small, because PQ changes to its reactive radical form by redox cycling reaction to produce active oxygen species only when incorporated into cells (Bismuth et al., 1990). Further, the amounts of PQ in the diets were almost unchanged for over $18 \mathrm{~h}$, which corresponded to the daily feeding period. PQ amount was determined by HPLC using the supernatant of a mixture of diet and $2 \%$ sulfosalicylic acid. The HPLC was carried out according to the method of Kage et al. (1998) except that Develosil C30UG5 (4.6×250 mm, Nomura Chemical Co., Nagoya) was used. The recovery percentages of PQ from the diets were $92-95 \%$.

The preventive effect of orally administered-ECCg in mice pretreated orally with PQ (Yonemitsu et al., 1999) may support that catechins can scavenge PQ radical or PQ -induced active oxygens after both catechins and PQ are absorbed. Therefore, it may also be necessary to compare the preventive effects among $\mathrm{EGCg}, \mathrm{EGC}$ and $\mathrm{EGC}+\mathrm{GA}$, and among $\mathrm{ECg}, \mathrm{EC}$ and $\mathrm{EC}+\mathrm{GA}$ in previously $\mathrm{PQ}$-fed rats.

The stronger preventive effects of EGCg compared with the mixture of EGC and GA, and of ECg compared with the mixture of $\mathrm{EC}$ and $\mathrm{GA}$ against oxidative stress might be due to easier incorporation into cells of EGCg and $\mathrm{ECg}$ in comparison with their components (EGC and GA, and EC and GA, respectively), and/or to stronger radical scavenging activity of EGCg and ECg in comparison with their components. Higher affinity of EGCg and $\mathrm{ECg}$, compared with EGC and EC, for lipid bilayer (Hashimoto et al., 1999) may suggest that EGCg and ECg can be incorporated more easily from the gastrointestinal tract than EGC and EC, respectively. However, the precise mechanism by which $\mathrm{EGCg}$ and $\mathrm{ECg}$ are more effective in preventing oxidative stress than their components remains to be further examined.

Although the appearance of orally administered $\mathrm{EGCg}, \mathrm{ECg}$, EGC, and EC into portal blood (Okushio et al., 1996), and recovery of orally administered EGCg from plasma, liver, and the brain (Nakagawa \& Miyazawa, 1997; Nakagawa et al., 1999) have been reported, differences in absorbability from the gastrointestinal tract between these catechins and their components, EGC, EC and GA have not yet been fully examined. It would be very interesting to examine the differences in absorbability among these compounds to identify the mechanism of the stronger preventive effects of $\mathrm{EGCg}$ and $\mathrm{ECg}$ compared to those effects when mixed with their components.

\section{References}

Bismuth, C., Garnier, R., Baud, F.J., Muszynski, J. and Keyes, C. (1990). Paraquat poisoning, an overview of the current status. Drug Safety, 5, 243-251.

Del Boccio, G., Lapenna, D., Porreca, E., Pannelli, A., Savini, F., Feliciani, P., Ricci, G. and Cuccurulle, F. (1990). Aortic antioxidant defense mechanism: Time-related changes in cholesterol-fed rabbits. Atherosclerosis, 81, 127-135.

Duncan, D.B. (1957). Multiple range tests for correlated and heteroscedastic means. Biometrics, 13, 164-176.

Folch, J., Lees, M. and Sloane-Stanley, G.H. (1957). A simple method for the isolation and purification of total lipides from animal tissues. J. Biol. Chem., 226, 497-509.

Fukuyo, M., Hara, Y. and Muramatsu, K. (1986). Effects of tea leaf catechin, (-)-epigallocatechin gallate, on plasma cholesterol level in rats. Nippon Eiyo Shokuryo Gakkaishi, 39, 495-500 (in Japanese).

Hashimoto, H., Kumazawa, S., Nanjo, F., Hara, Y. and Nakayama, T. (1999). Interaction of tea catechins with lipid bilayers investegated with liposome systems. Biosci. Biotechnol. Biochem., 63, 22522255.

Hara, Y. (1994). Prophylactic functions of tea polyphenols. In "Food Phytochemicals for Cancer Prevention II," ed. By C-T. Ho, T. Osawa, M-T. Huang and R.T. Rosen. American Chemical Society, 547, Washington, DC, pp. 34-50.

Igarashi, K., Suzuki, O., Hara, Y., Yoshiki, Y. and Okubo, K. (1998). Comparison of the protective effects of epigallocatechin gallate and epigallocatechin on paraquat-induced oxidative stress in rats. Food Sci. Technol. Int. Tokyo, 4, 149-154.

Igarashi, K. , Suzuki, O. and Hara, Y. (1999). Comparison of the preventive effects of epigallocatechin gallate, epicatechin gallate and epicatechin on paraquat-induced oxidative stress in rats. Food Sci. Technol. Res., 5, 69-73.

Ikigai, H., Nakano, T., Hara, Y. and Shimamura, T. (1993). Bacteriocidal catechins damage the lipid bilayer. Biochim. Biophys. Acta, 1147, 132-136.

Kada, T., Kaneko, K., Matsuzaki, S., Matsuzaki, T. and Hara, Y. (1985). Detection and chemical identification of natural bio-antimutagens, a case of the green tea factor. Nutr. Res., 150, 127-135.

Kage, S., Kudo, K., Fukushima, S. and Ikeda, N. (1998). Selective determination of paraquat and diquat in blood by high-performance liquid chromatography and high-performance liquid chromatography/mass spectrometry. Jpn. J. Forensic Toxicol., 16, 34-41.

Lowry, O.H., Rosenbrough, N.J., Farr, A.J. and Randall, R.J. (1951). Protein measurement with the Folin phenol reagent. J. Biol. Chem., 193, 265-275.

Nakagami, T., Nanaumi-Tamura, N., Toyomura, K., Nakamura, T. and Shigehisa, T. (1995). Dietary flavonoids as potential natural biological response modifiers affecting the autoimmune system. J. Food Sci., 60, 653-656.

Nakagawa, K. and Miyazawa, T. (1997). Absorption of and distribution of tea catechins, (-)-epigallocatechin-3-gallate, in the rat. $J$. Nutr. Sci. Vitaminol., 43, 679-684.

Nakagawa, K., Ninomiya, M., Okubo, T., Aoi, N., Juneja, L.R., Kim, M., Yamanaka, K. and Miyazawa, T.(1999). Tea catechin supplementation increases antioxidant capacity and prevents phospholipid hydroperoxidation in plasma of humans. J. Agric. Food Chem., 47, 3967-3973.

Okushio, K., Matsumoto, N., Kohri, T., Suzuki, M., Nanjyo, F. and Hara, Y. (1996). Absorption of tea catechins into rat portal vein. Biol. Pharm. Bull., 19, 326-329.

Reeves, P.G., Nielsen, F.H. and Fahey, G.C. (1993). AIN-93 purified diets for laboratory rodents: Final report of the American Institute of Nutrition Ad Hoc Writing Commitee on the reformulation of the AIN-76A rodent diet. J. Nutr., 123, 1939-1951.

Susanne, V., Barbara, T., Davids, A., Gerald, W., Mary, K., Julie, W. and Jose, G. (1996). Inhibitory effect of six green tea catechins and caffeine on the growth of four selected human tumor cell lines. AntiCancer Drugs, 7, 461-468.

Toda, H., Okubo, S., Hara, Y. and Shimamura, T. (1991). Antibacterial and bactericidal activities of tea extracts and catechins against methicillin resistant Staphylococcus aureus. Nippon Saikingaku Zasshi, 46, 839-845 (in Japanese).

Tomita, K. and Sano, M. (1983). In "Kasanka Shishitsu Jikkenho," ed. by T. Kaneda. and N. Ueda. Ishiyaku Shuppan Co., Tokyo, pp. 149 150 (in Japanese).

Van'T Hooft, F.M. and Van Tol, A. (1985). Discrepancies in the catabolic pathway of human and rat high-density lipoprotein apolipoprotein A-I in the rat. Eur. J. Clin. Invest., 15, 395-402.

Yen, G-C. and Chen, H-Y. (1995). Antioxidative activity of various tea extracts in relation to their antimutagenecity. J. Agric. Food Chem., 43, 27-32

Yonemitsu, K., Koreeda, A., Higuchi, A. and Tsunenari, S.(1999). Protective effects of green tea and epigallocatechin gallate against paraquat toxicity in mice. Jpn. J. Toxicol., 12, 143-150.

Yoshizawa, S., Horiuchi, T. and Fujiki, H. (1987). Antitumor promoting activity of (-)-epigallocatechin gallate, the main constituent of "Tannin" in green tea. Phytother. Res., 1, 44-47. 